\title{
DA INCONSTITUCIONALIDADE DA SOLUÇÃO DE CONSULTA DA COORDENAÇÃO GERAL DE TRIBUTAÇÃO N. 542
}

\author{
THE UNCONSTITUTIONALITY OF THE CONSULTATION SOLUTION OF THE \\ GENERAL COORDINATION OF TAXATION N. 542
}

\author{
Ives Gandra da Silva Martins \\ Professor Emérito da Universidade Mackenzie em cuja Faculdade de Direito foi Titular de \\ Direito Constitucional; E-mail: ivesgandra@gandramartins.adv.br
}

\author{
Fátima Fernandes Rodrigues de Souza \\ Advogada em São Paulo e Professora do Centro de Extensão Universitária. \\ E-mail:fatima.souza@gandramartins.adv.br
}

Convidados

\begin{abstract}
RESUMO: Tendo em vista a necessidade de expansão no oferecimento de serviços na área de saúde, instituições do terceiro setor, a despeito da verba insuficiente repassada pelo Sistema Único de Saúde viabilizam projetos por meio da celebração de parcerias com empresas lucrativas, tanto no modelo de contratos de prestação de serviço ou no modelo de sociedade. No tocante a essa última modalidade, as entidades consideram participar como sócias de sociedades com fins lucrativos, com atividades tributadas. Nesse particular, as entidades teriam uma participação societária junto com outros parceiros, filantrópicos ou não, sem a transmissão de título associativo ou sua transformação em pessoa jurídica tributada e face de proibição legal existente. No entanto, a Solução de Consulta da Coordenação Geral de Tributação n. 542 entendeu que a participação em sociedade de escopo econômico implica a perda de imunidade tributária dessas instituições. Cumpre analisar nesse artigo a constitucionalidade da referida Consulta.
\end{abstract}

Palavras-chaves: Imunidade tributária: Terceiro Setor; Sistema Único de Saúde

\begin{abstract}
Considering the need for expansion in the provision of health services, third sector institutions, despite insufficient funds passed through the Unified Health System, enable projects through the conclusion of partnerships with profitable companies, both in the model of contracts of or in the model of society. With regard to this last modality, the entities consider participating as members of profit-making companies with taxed activities. In this particular case, the entities would have a shareholding with other partners, philanthropic or not, without the transfer of an associative title or their transformation into a taxed legal entity and with an existing legal prohibition. However, the Consultation Solution of the General Coordination of Taxation n. 542 understood that the participation in society of economic scope implies the loss of tax immunity of these institutions. It is necessary to analyze in this article the constitutionality of said Consultation.
\end{abstract}

Keywords: Tax immunity: Third Sector; Health Unic System 
Algumas instituições do $3^{\circ}$ Setor, especialmente as dedicadas ao campo da saúde, desejando expandir a oferta de serviços, malgrado a insuficiência das verbas que lhes são repassadas pelo SUS, buscam viabilizar seus projetos mediante a celebração de parcerias com empresas lucrativas, seja no modelo de contratos de prestação de serviços, seja no modelo de sociedade.

Especificamente em relação à essa última modalidade, as entidades consideram participar como sócias de sociedades com fins lucrativos, com atividades regularmente tributadas. As entidades teriam, então, uma participação societária juntamente com outros parceiros, filantrópicos ou não, sem a transmissão de título associativo ou sua transformação em PJ tributada, ante a vedação legal existente.

No entanto, tais entidades foram surpreendidas com a Solução de Consulta da Coordenação Geral de Tributação (COSIT) n. 542, datada de 04/12/2017 e publicada em 13/12/2017, segundo a qual a participação em sociedade de escopo econômico implicaria a perda da imunidade tributária de tais instituições, como se vê do teor do ato administrativo:

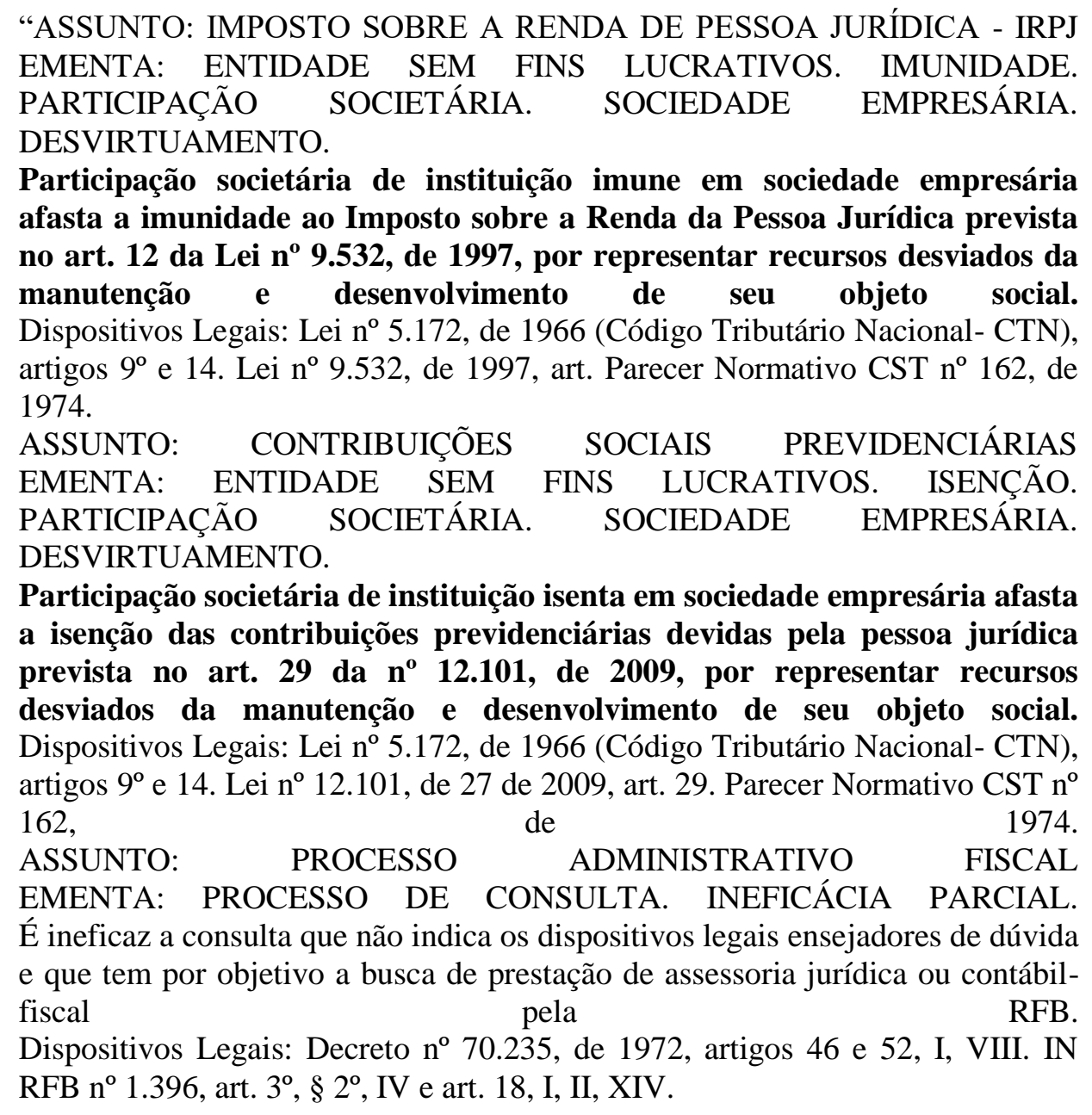

À evidência, referido ato gerou insegurança jurídica, quanto à possibilidade de tais entidades integrarem uma empresa de finalidade lucrativa como sócias, ante o risco de perderem sua desoneração tributária, quer relativamente a impostos, quer a contribuições sociais, bem como quanto aos possíveis desdobramentos administrativos e judiciais e chances de êxito.

No entanto, o entendimento manifestado na Solução de Consulta COSIT 542 contraria flagrantemente a Constituição.

$\mathrm{O}$ art. 150, IV "c" da CF estabelece que: 
“Art. 150 Sem prejuízo de outras garantias asseguradas ao contribuinte, é vedado à União, aos estados, ao Distrito Federal e aos Municípios:

VI instituir impostos sobre:

c) patrimônio, renda ou serviços dos partidos políticos, inclusive suas fundações, das entidades sindicais dos trabalhadores, das instituições de educação e de assistência social, sem fins lucrativos, atendidos os requisitos da lei.

$\S 4^{\circ}$ As vedações expressas no inciso VI, alíneas b e c, compreendem somente o patrimônio, a renda e os serviços, relacionados com as finalidades essenciais das entidades nelas mencionadas" (negritamos).

O Supremo Tribunal Federal, há muito tempo, já reconheceu que a desoneração inserta nesse dispositivo é uma IMUNIDADE, da mesma forma que aquela prevista no art. $195, \S 7^{\circ}$ da CF.

$\mathrm{O} \S 4^{\mathrm{o}}$, do art. 150 da $\mathrm{CF}$, limita a imunidade aos impostos incidentes sobre o patrimônio, a renda e os serviços relativos às atividades essenciais da entidade. $\mathrm{O}$ fato de estabelecer essa limitação por si só já deixa evidente que a Constituição admite que as instituições referidas na alínea "c", a par de suas finalidades assistenciais, possam exercer outras atividades, inclusive de natureza econômica, para proteger seu patrimônio, otimizar os recursos de que dispõem ou mesmo gerar os necessários à manutenção de seus objetivos institucionais, sem perder a natureza de entidades beneficentes de assistência social.

Tendo em vista que as atividades assistenciais demandam recursos expressivos e contínuos - nem sempre se mostrando suficientes aqueles provenientes de doações, bens patrimoniais ou os gerados pela prestação onerosa de serviços relativos a suas atividades institucionais aos que podem por eles pagar - é razoável admitir que a entidade possa exercer outras atividades, inclusive de natureza econômica no sentido de reforçar os recursos para o desenvolvimento de suas finalidades institucionais. O princípio da razoabilidade exige, entretanto, que as atividades econômicas mantidas pela entidade com esse fim tenham caráter verdadeiramente subsidiário, não se mostrando, ademais, contrários aos objetivos sociais da instituição.

Para evitar que a imunidade dê ensejo a condutas abusivas, de vez que, o exercício de uma atividade econômica livre de impostos colocaria a empresa em situação de privilégio em relação às demais do mesmo setor, podendo produzir distúrbios de ordem concorrencial, a Constituição houve por bem determinar que a renda daí advinda, o patrimônio aplicado e as operações de produção, circulação ou prestação de serviços desenvolvidas sofressem tributação, quando revertidos à entidade imune.

Como bem observa Ives Gandra da Silva Martins: ${ }^{1}$

"Ora, o Texto Constitucional atual objetivou, na minha opinião, eliminar, definitivamente, tal possibilidade, sendo que a junção do princípio estatuído nos artigos $173, \S 4^{\circ}$ e $150, \S 4^{\circ}$ impõe a exegese de que as atividades, mesmo que relacionadas indiretamente com aquelas essenciais das entidades imunes enunciadas nos incs. "b" e "c" do artigo 150, VI, se forem idênticas ou análogas às de outras empresas privadas, não gozariam da proteção imunitória. Exemplificando: uma entidade imune tem um imóvel e o aluga. Tal locação não constitui atividade econômica desrelacionada de seu objetivo nem fere o mercado ou representa uma concorrência desleal. Tal locação do imóvel não

${ }^{1}$ Comentários à Constituição do Brasil, Saraiva, no 6, tomo I, p. 206.

Revista de Direito Brasileira | São Paulo, SP | v. 20 | n. 8 | p. 465-474 |Mai./Ago. 2018 
exige, pois, incidência do IPTU ou goza a entidade de imunidade para não pagar imposto de renda. A mesma entidade, todavia, para obter recursos para suas finalidades decide montar uma fábrica de sapatos, porque o mercado da região está sendo explorado por outras fábricas de fins lucrativos, com sucesso. Nesta hipótese, a nova atividade embora indiretamente referenciada, não é imune, porque poderia ensejar a dominação de mercado ou a eliminação de concorrência sobre gerar lucros não tributáveis exagerados se comparados com os seus concorrentes."

Com efeito, se pudessem, as entidades de que trata a alínea "c" da norma constitucional em análise, gozar de imunidade também em relação a atividades econômicas por elas exploradas, ainda que com o objetivo de gerar recursos para suas finalidades institucionais, ficariam em situação de vantagem em relação a empresas que tivessem como objetivo social as mesmas atividades econômicas, levando à concorrência desleal proibida pelo art. $173, \S 4^{\circ} \mathrm{da} \mathrm{CF} .^{2}$

Tenha-se presente, ademais, que a teleologia da imunidade é incentivar o desenvolvimento de atividades assistenciais, e não de atividades econômicas ou especulativas, que podem mesmo gerar riscos para o pleno atingimento das finalidades institucionais.

Por essa razão, o desempenho de atividade econômica pela entidade imune há de ser ancilar e compatível com o fim institucional, sendo tributado quando assumir expressão passível de ocasionar distúrbios nas relações de concorrência, o que deve ser analisado caso a caso.

A tributação restará afastada, se a atividade econômica exercida pela empresa de que participe a instituição não for suscetível de ensejar desequilíbrio concorrencial, quer por ser insipiente, quer por estar umbilicalmente ligada ao exercício da atividade assistencial, como ocorreria, por exemplo, se, em instituição confessional dedicada à educação de menores carentes, para reforçar os recursos necessários ao desempenho das atividades essenciais, as religiosas educadoras mantivessem também pequena produção e comercialização de doces ou licores caseiros.

Na mesma linha, o Supremo Tribunal Federal firmou jurisprudência de que não são tributados os serviços prestados em estacionamento de veículos no pátio interno de entidade hospitalar, nem a renda deles proveniente destinada ao custeio das atividades essenciais da entidade.

No tocante à tributação do patrimônio da entidade, a jurisprudência da Corte Suprema tem entendido que ela só se legitima se os bens forem usados para atividades econômicas, - de cunho diverso, portanto, das assistenciais. Já quando utilizados como infraestrutura de apoio para o desempenho destas, a imunidade prevalece.

É o que se verifica da decisão proferida no RE 221.395-8/SP, em relação a entidade cuja finalidade era difundir a bíblia e cuidar da formação de jovens. O Tribunal decidiu, que bens imóveis destinados a utilização como escritórios e a servir de moradia gratuita aos membros engajados nas ações institucionais, não estão sujeitos a IPTU, deixando claro, entretanto, que imóveis utilizados para outras atividades diversas das finalidades institucionais da entidade não estão a salvo da tributação:

"O fato, portanto, de os imóveis estarem destinados a servir de escritório e residência para membros da impetrante, para missionários, bem como para depósito de materiais não os fez sujeitos à incidência do Imposto Predial e Territorial Urbano. Tal destinação viabiliza a própria atividade da impetrante. Uma coisa é verificar-se, tal como retratada no acórdão proferido, a utilização

\footnotetext{
${ }^{2}$ Art. 173 - Ressalvados os casos previstos nesta Constituição, a exploração direta de atividade econômica pelo Estado só será permitida quando necessária aos imperativos da segurança nacional ou a relevante interesse coletivo, conforme definidos em lei. $\S 4^{\circ}$ - A lei reprimirá o abuso do poder econômico que vise à dominação dos mercados, à eliminação da concorrência e ao aumento arbitrário dos lucros".
} 
dos imóveis como a encerrar o local de trabalho daqueles que estão engajados na missão e a residência destes. Outra totalmente diversa diria respeito à utilização dos imóveis para finalidades estranhas aos estatutos da impetrante, passando esta a ombrear com pessoas naturais e jurídicas de direito privado integradas ao mercado, competindo, assim, em verdadeira atividade econômica. Conforme salientado por Ives Gandra da Silva Martins, em "Comentários à Constituição do Brasil", Saraiva, no. 6, tomo I, a pedra de toque, o elemento definidor da incidência do preceito revelador da imunidade é o fato de não se ter exploração de atividade econômica" ${ }^{3}$.

A nosso ver, se a gestão que a entidade faz de seus bens patrimoniais aplicando-os em atividades lucrativas apresenta um caráter verdadeiramente subsidiário em relação às suas atividades essenciais, resumindo-se à adoção de meios adequados a evitar a perda patrimonial e assegurar o fluxo de recursos necessário a garantir a continuidade de seus fins institucionais, o resultado que possa advir dessa atuação estará abrangido pela imunidade.

A situação será diversa se os meios de "gestão" do patrimônio e das rendas evidenciarem exploração de atividade econômica com intuito empresarial. É óbvio que, nesse caso, mesmo que os recursos resultantes sejam destinados aos objetivos estatutários da entidade, a renda advinda dessa atividade deverá ser tributada, assim como o próprio patrimônio nela aplicado, submetendo-se ao mesmo regime das empresas do setor econômico respectivo.

Seguindo esses critérios, é inegável que aluguéis percebidos por entidades imunes, como, por exemplo, as Santas Casas de Misericórdia, decorrentes da locação de imóveis de sua propriedade e destinados a custear suas finalidades institucionais, estão abrangidos pela imunidade, até porque a administração de patrimônio próprio não produz efeitos concorrenciais. O mesmo não se poderia dizer se, em algum desses imóveis, a entidade resolvesse explorar um shopping center, pois aí, a atividade se distanciaria da mera gestão do patrimônio, para transformar-se em atividade empresarial, que o Constituinte não teve por escopo estimular, ao conceder a imunidade.

Da mesma forma, se as aplicações que a entidade educacional ou assistencial faz de suas receitas no mercado financeiro são proporcionais e compatíveis com o fluxo da utilização dos recursos em suas atividades institucionais, a denotar o intuito de incrementá-los com investimentos seguros e de preservá-los da corrosão inflacionária até o momento adequado para sua utilização nas finalidades essenciais a que se dedica, não se configura exploração de atividade com cunho empresarial, mas apenas gestão ou administração de patrimônio ou da renda da entidade, vinculados às próprias finalidades essenciais a que se dedica.

Nesse sentido, revela-se, evidente a absoluta impossibilidade jurídica de as entidades referidas na alínea "c" do inciso VI do art. 150 da CF sofrerem tributação pelos impostos federais sobre os rendimentos das aplicações financeiras realizadas para a preservação e incremento dos recursos destinados à manutenção de suas finalidades sociais, como decidiu o Supremo Tribunal Federal ao conceder cautelar na ADIn $n^{\circ} 1802-7 / 600$, para o fim de suspender a eficácia do $\S 1^{\circ}$ do art. 12 da Lei 9532/97, por confronto com a imunidade em tela.

Já a mesma intributabilidade não se poderia sustentar quanto a resultados advindos de investimentos de risco, como, por exemplo, os ganhos auferidos em mercados de capitais, por incompatíveis com a segurança que deve nortear a gestão do patrimônio da entidade com vistas à perenidade dos fins institucionais.

As mesmas considerações tecidas até aqui em relação a impostos valem para a imunidade das entidades beneficentes de assistência social relativamente a contribuições sociais destinadas à seguridade social, previstas nos artigos 195 e 239 da CF, incidentes sobre 
faturamento ou receitas (COFINS), sobre o faturamento e folha de salários (entidades sem fins lucrativos) (PIS), sobre o lucro (CSLL) e sobre folha de salários (quota patronal).

O $\S 7^{\circ}$ do art. 195 da CF estabelece:

"§ $7^{\circ}$ - São isentas de contribuição para a seguridade social as entidades beneficentes de assistência social que atendam às exigências estabelecidas em lei."

Não obstante na redação do dispositivo tenha sido utilizado o termo "isenção", tratandose de desoneração veiculada pelo texto constitucional, configura verdadeira imunidade, consoante já decidiu o Supremo Tribunal Federal, lastreado em voto do Ministro Celso de Mello:

"Impende enfatizar, neste ponto, um aspecto da mais alta relevância. Mais importante do que a própria discussão sobre o alcance da norma inscrita em simples ato de caráter infraconstitucional editado pelo Poder Público (DL $\mathrm{n}^{\circ} 1.572 / 77$, art. $1^{\circ}, \S 1^{\circ}$ ), revela-se a análise da cláusula inscrita no art. $195, \S 7^{\circ}$, da Carta da República, que outorga a entidades beneficentes de assistência social - desde que atendam às exigências estabelecidas em lei - benefício extraordinário da imunidade subjetiva referente às contribuições pertinentes à seguridade social. (MS 22.192-DF (DJ 19/12/96)

Com a superveniência da Constituição Federal de 1988, outorgou-se às entidades beneficentes de assistência social, em norma definidora de típicas hipóteses de imunidade, uma expressiva garantia de índole tributária em favor dessas instituições civis.

A cláusula inscrita no art. $195, \$ 7^{\circ}$, da Carta Política - não obstante referir-se impropriamente à isenção de contribuição para seguridade social -, contemplou as entidades beneficentes de assistência social com o favor constitucional da imunidade tributária, desde que por elas preenchidos os requisitos fixados em lei (ROQUE ANTONIO CARRAZZA, "Curso de Direito Constitucional Tributário", p. 349 nota de rodapé $\mathrm{n}^{\circ}$ 144, $5^{\mathrm{a}}$ ed., 1993, Malheiros; JOSÉ EDUARDO SOARES DE MELO, "Contribuições Sociais no Sistema Tributário", p. 171-175, 1995, Malheiros; SACHA CALMON NAVARRO COÊLHO, "Comentários à Constituição de 1988 - Sistema Tributário", p.41-42,

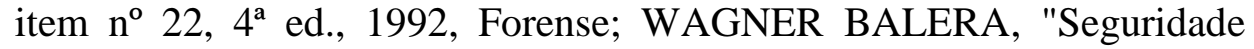
Social na Constituição de 1988", p. 71, 1989 RT, v.g.).

Convém salientar que esse magistério doutrinário reflete-se na própria jurisprudência constitucional do Supremo Tribunal Federal, que já identificou na cláusula inscrita no art. 195, $§ 7^{\circ}$, da Carta Política, a existência de uma típica garantia de imunidade estabelecida em favor das entidades beneficentes de assistência social (RTJ 137/965, Rel. Min. MOREIRA ALVES)."

A interpretação sistemática desse dispositivo com a norma do art. 146 II da CF, deixa nítido que a lei a que a parte final do $\S 7^{\circ}$ do art. 195 da $\mathrm{CF}$ faz referência, só pode ser lei complementar, já que a esta cabe regular as limitações ao poder de tributar, como é o caso da imunidade.

Não tendo, até agora, sido editada lei dessa estatura, o Supremo Tribunal Federal considera prestante para disciplinar os requisitos que as entidades devem preencher para fazerem 
jus a essa desoneração, o art. 14 do CTN, até porque, o perfil do conceito de entidade que consta no $\S 7^{\circ}$ do art. 195 da CF, é o mesmo que aparece no art. 150 VI c da Lei Maior, a teor da jurisprudência da Suprema Corte (RE 22.360-3-DF, DJ 12.12.95).

A lei ordinária federal $n^{\circ} 9732 / 98$ procurou diferenciá-los, exigindo que, para fazer jus à imunidade de contribuições sociais, a entidade exercesse suas atividades em regime de filantropia, assim considerada a exclusiva gratuidade ou com elevada porcentagem de atendimentos ao SUS.

Entretanto, essas exigências foram consideradas pelo Supremo Tribunal Federal como atentatórias à norma de imunidade, quer por pretenderem limitar materialmente o âmbito da norma de desoneração constitucional, quer porque, a teor do art. 146, II da CF, somente lei complementar pode estabelecer requisitos para gozo da imunidade.

Foram nesse sentido as decisões da Suprema Corte, em ações de controle concentrado (ADPF 2028, 2228, 2621) e em incidente de repercussão geral (RE566.622) - em que fixou-se a tese n. 32, no sentido de que "ante a Constituição Federal, que a todos indistintamente submete, a regência da imunidade faz-se mediante lei complementar". Tais decisões, a teor dos arts. 102, $\$ 2^{\circ}$ e $3^{\circ}$ da CF, 543 A, 543 B e $543 \mathrm{C}$ do CPC, são vinculantes tanto para o judiciário como para a administração, de forma que não cabe à legislação ordinária impor outros requisitos, inclusive de natureza procedimental, ao gozo dessa desoneração constitucional, que não os do art. 14 do CTN. Certificados e outros tipos de atos administrativos destinados a atestar a natureza da entidade têm natureza meramente declaratória, não podendo interferir nessas espécies de limitações ao poder de tributar.

Assim, entidades beneficentes de assistência social dedicadas às áreas da saúde, educação e assistência social que atendam aos requisitos dos artigos $9^{\circ}$ e 14 CTN são imunes às contribuições sociais destinadas à seguridade social, incidentes sobre o lucro (CSL), o faturamento ou a receita (PIS e COFINS) e sobre a folha de salários (PIS e QUOTA PATRONAL) e demais rendimentos do trabalho.

No mesmo sentido, o STJ, em estrito acatamento à diretriz do STF, editou a Súmula 612, pela qual "o certificado de entidade beneficente de assistência social (CEBAS), no prazo de sua validade, possui natureza declaratória para fins tributários, retroagindo seus efeitos à data em que demonstrado o cumprimento dos requisitos estabelecidos por lei complementar para a fruição da imunidade".

Feitas essas considerações, constatamos que, confrontando o conteúdo da Solução de Consulta COSIT 524, de 04/12/2017 com o disposto no $\$ 4^{\circ}$ do art. 150 da CF, resulta evidente que ele viola frontalmente o dispositivo constitucional, uma vez que a referida norma deixa claro que, guardados os limites aqui expostos, a participação em empresa lucrativa não desnatura a imunidade da entidade beneficente de assistência social, assegurada pelo art. 150, VI, "c" da CF e pelo art. $195, \S 7^{\circ}$ da $\mathrm{CF}$

Com efeito, o parágrafo $4^{\circ}$, do art. 150, VI, “c” da CF expressamente admite participação dessa natureza, sem que isso implique perda de imunidade. Apenas estabelece que, quanto a tais atividades, sejam recolhidos os tributos incidentes.

No entanto, o Supremo Tribunal Federal, reconhecendo a relevância da participação da sociedade nas ações de saúde, educação e assistência social, que ajudam o Estado a desincumbirse de atendimentos que, sem esse apoio, não teria condições de prover à coletividade, atribuiu a esse $\S 4^{\circ}$ interpretação que abrandou a exigência nele contida, desde que os resultados obtidos com a atividade lucrativa sejam aplicados no escopo institucional.

É o que se vê de sua jurisprudência consolidada na Súmula 724 e nos seguintes Arestos: "Súmula 724: Ainda quando alugado a terceiros, permanece imune ao IPTU o imóvel pertencente a qualquer das entidades referidas pelo art. 150, VI, c, da Constituição, desde que o valor dos aluguéis seja aplicado 
nas atividades essenciais de tais entidades" (DJ de 09/12/2003, p. 1; DJ de 10/12/2003, p. 1; DJ de 11/12/2003, p. 1.).

"Recurso extraordinário. SENAC. Instituição de educação sem finalidade lucrativa. ITBI. Imunidade. - Falta de prequestionamento da questão relativa ao princípio constitucional da isonomia. - Esta Corte, por seu Plenário, ao julgar o RE 237.718, firmou o entendimento de que a imunidade tributária do patrimônio das instituições de assistência social (artigo 150, VI, "c", da Constituição) se aplica para afastar a incidência do IPTU sobre imóveis de propriedade dessas instituições, ainda quando alugados a terceiros, desde que os aluguéis sejam aplicados em suas finalidades institucionais. - Por identidade de razão, a mesma fundamentação em que se baseou esse precedente se aplica a instituições de educação, como a presente, sem fins lucrativos, para ver reconhecida, em seu favor, a imunidade relativamente ao ITBI referente à aquisição por ela de imóvel locado a terceiro, destinando-se os aluguéis a ser aplicados em suas finalidades institucionais. Recurso extraordinário não conhecido." (RE 235.737 / SP, Rel. Moreira Alves,DJ 17-05-2002 PP00067)

"EMENTA: Imunidade tributária do patrimônio das instituições de assistência social (CF, art. 150, VI, c): sua aplicabilidade de modo a préexcluir a incidência do IPTU sobre imóvel de propriedade da entidade imune, ainda quando alugado a terceiro, sempre que a renda dos aluguéis seja aplicada em suas finalidades institucionais." (RE 237.718-6, Rel. Min. Sepúlveda Pertence, j. 29/03/2001)

"Agravo regimental no recurso extraordinário com agravo. Tributário. IPTU. Imunidade. Entidade de assistência social sem fins lucrativos. Locação de imóvel. Súmula no $724 / \mathrm{STF}$. Comprovação dos requisitos para reconhecimento da imunidade. Controvérsia decidida à luz da legislação infraconstitucional e do conjunto fático-probatório. Súmula $\mathrm{n}^{\circ}$ 279/STF. Ônus da prova.

1.O Tribunal de origem não divergiu da orientação da Corte no sentido de que a regra imunizante contida no art. 150, VI, c, da Constituição Federal afasta a incidência do IPTU sobre os imóveis de propriedade das instituições de assistência social sem fins lucrativos, mesmo que alugados a terceiros, desde que o valor dos aluguéis seja aplicado nas suas atividades essenciais (Súmula no 724/STF).

2. O acórdão recorrido concluiu pelo enquadramento da instituição como entidade de assistência social sem fins lucrativos, a partir da análise dos requisitos previstos no art. 14 do Código Tributário Nacional. Para ultrapassar o entendimento consagrado pelo Tribunal a quo, necessário seria o reexame dos fatos e das provas e da legislação infraconstitucional de regência. Precedentes.

3. A presunção de que o imóvel ou as rendas da entidade assistencial reconhecidamente imune estão afetados às suas finalidades institucionais milita em favor da entidade. Cabe ao Fisco elidir a presunção, mediante a constituição de prova em contrário. 4. Agravo regimental não provido" (ARE 760.876-AgR/SE, Rel. Min. Dias Toffoli, $1^{\mathrm{a}}$ Turma - grifei). 
"AGRAVO REGIMENTAL EM AGRAVO DE INSTRUMENTO. IPTU. IMUNIDADE. ENTIDADE DE ASSISTÊNCIA SOCIAL. IMÓVEL ALUGADO. PRECEDENTE.

A imunidade das entidades de assistência social prevista no artigo 150, VI, C, da Constituição, abrange o IPTU incidente sobre imóvel alugado a terceiro, cuja renda é destinada às suas finalidades essenciais. Agravo regimental a que se nega provimento" (AI 501.686-AgR/MG, Rel. Min. Eros Grau, $1^{\text {a }}$ Turma - grifei)

\section{"IMUNIDADE E EXPLORAÇÃO DE ESTACIONAMENTO.}

Entendo que a imunidade tributária conferida a instituições de assistência social sem fins lucrativos (CF/69, art. 19, III, “c": CF/88, art. 150, VI, "c" abrange inclusive os serviços que não se enquadrem em suas finalidades essenciais, a Turma reformou acórdão que sujeitara à incidência do ISS o serviço de estacionamento de veículos prestado por hospital em seu pátio interno. Precedente Citado: RE 116.188 (RTJ 131/1295); RE 144.900-SP (DJU de 26/09/97), j. 21/09/99.

(Informativo do STF n ${ }^{\circ} 163$ )"

Acerca desse aspecto, assim se manifestou a perícia:

“A Lei no 9656/98, dispõe sobre planos e seguros privados de assistência à saúde. Em 10.08.1998, foi firmado o Contrato Social de Constituição da Plasac Sociedade Civil Ltda., tendo como sócio majoritária a Sociedade Brasileira e Japonesa de Beneficência Santa Cruz, ora Requerente, com 19.998 quotas, e os Srs. Jorge Nagano e Kozo Denda, ambos com 1 quota cada um, passando a Plasac a ser a única controlada da requerente.

A Requerente transferiu para Plasac S/C Ltda., a partir de 01.11.1998, todos os direitos e obrigações decorrentes dos 2.037 contratos ativos, na modalidade de contratos individuais, contratos funcionários e contratos empresas, conforme Cessão de Contrato de Plano de Saúde.(...)

Importante esclarecer que, por definição, "Controlada é a entidade na qual a controladora tem o poder de assegurar de forma permanente, preponderância em suas deliberações sociais e de eleger a maioria de seus administradores.

A partir dessas premissas tem-se que a transferência patrimonial da entidade para com a Plasac foi de $99,99 \%$, enquanto que a terceiros $0,1 \%$, portanto, smj, não representou desvio das finalidades institucionais da requerente" (grifamos) (FLS. 896).

Assim, a participação em entidades lucrativas não caracteriza necessariamente transferência patrimonial da entidade para a empresa criada, nem desvio de suas finalidades institucionais, não tendo a legislação ordinária a que o ato administrativo faz remissão, força para se sobrepor ao que está estabelecido na Lei Maior. Tanto que outras entidades sem fins lucrativos, como, por exemplo, as Santas Casas de Misericórdia, participam e mesmo controlam 
empresas com fins lucrativos que operam planos de saúde, sem perderem o direito à imunidade, quer de impostos, quer de contribuições sociais.

Repita-se: o simples fato de participar de empresas com escopo econômico não desnatura a entidade como de finalidade não lucrativa beneficiária da imunidade de impostos e de contribuições sociais. Aliás, na área da saúde, tendo em vista que o SUS há mais de 10 anos não atualiza o valor dos procedimentos médicos, graças às receitas que tais entidades obtêm com a atividade lucrativa por elas exercida, podem atender a população carente, SUBSIDIANDO o Estado e cumprindo plenamente sua atividade institucional. Melhor será se puderem contar com o incremento desses recursos com outros advindos de sociedade empresária em que tenha participação.

É importante salientar, como observado acima, que, para que o resultado auferido com tais participações seja abrangido pela imunidade, é necessário que a atividade desempenhada pela empresa de que a entidade venha a participar apresente um caráter verdadeiramente subsidiário em relação às atividades essenciais da entidade e que os recursos advindos dessa participação sejam aplicados nas finalidades institucionais da entidade. Resumindo: essa participação deve consistir na busca de meios adequados para incrementar os recursos destinados a evitar a perda patrimonial e assegurar o fluxo de recursos necessário a garantir a continuidade das finalidades institucionais das entidades do $3^{\circ}$ setor.

A situação será diversa se os meios de "gestão" do patrimônio e das rendas evidenciarem exploração de atividade econômica com intuito empresarial. É óbvio que, nesse caso, mesmo que os recursos resultantes sejam destinados aos objetivos estatutários da entidade, a renda advinda dessa atividade deverá ser tributada, assim como o próprio patrimônio nela aplicado, submetendo-se ao mesmo regime das empresas do setor econômico respectivo.

Quanto às consequências que poderão advir para as entidades que ingressarem como sócias em empresa de escopo econômico, poderão consistir em questionamentos por parte do fisco, mediante procedimento administrativo de desconsideração da imunidade e lavratura de autos de infração, com exigência de tributos não recolhidos, uma vez que a Receita Federal não prima pelo cumprimento da Constituição nem pelo respeito à Jurisprudência do STF.

Caso a entidade deseje acautelar-se contra esses procedimentos, uma vez decidida a participação em sociedade lucrativa e definida a atividade desta, poderá impetrar Mandado de Segurança preventivo para assegurar seu direito líquido e certo de continuar gozando da imunidade de tributos, mesmo que participe de empresa lucrativa, nos termos do art. 150, IV, "c", $\S 4^{\circ}$ da CF e da jurisprudência do STF, com o consequente reconhecimento da inconstitucionalidade do entendimento COSIT n. 524. Poderá ser requerida liminar para evitar a instauração de procedimentos administrativos destinados a excluir a imunidade, lavratura de autos de infração para a exigência de tributos, inscrição no CADIN e outras medidas coativas.

\section{A2018-034 COSIT 542 artigo IVES E FAT}

